\title{
Effect of Fluticasone and Salmeterol on Tracheal Responsiveness to Ovalbumin and Lung Inflammation, Administrated during and after Sensitization
}

\author{
Zahra Gholamnezhad, ${ }^{1}$ Mohammad Hossain Boskabady, ${ }^{1}$ Mohammad Reza Khazdair, ${ }^{2}$ \\ Mahmoud Hosseini, ${ }^{1}$ and Mahdi Abbasnejad ${ }^{2}$ \\ ${ }^{1}$ Neurogenic Inflammation Research Centre, School of Medicine, Mashhad University of Medical Sciences, Mashhad 9177948564, Iran \\ ${ }^{2}$ Department of Biology, Faculty of Sciences, Kerman University of Shahid Bahonar, Kerman 9177948564, Iran
}

Correspondence should be addressed to Mohammad Hossain Boskabady; boskabadymh@mums.ac.ir

Received 31 August 2013; Accepted 12 November 2013; Published 19 January 2014

Academic Editors: J.-Y. Shih and F. Varoli

Copyright (C) 2014 Zahra Gholamnezhad et al. This is an open access article distributed under the Creative Commons Attribution License, which permits unrestricted use, distribution, and reproduction in any medium, provided the original work is properly cited.

\begin{abstract}
The effect of duration of administration of fluticasone propionate and salmeterol on tracheal responsiveness to ovalbumin and total and differential white blood cell in sensitized guinea pig was examined. Six groups of guinea pigs $(n=7)$ were sensitized to ovalbumin. Three groups of them were subjected to inhaled fluticasone propionate and salmeterol, one group during sensitization (A), one group after that (for 18 days, B), and the other one during sensitization but with 18 days delay before measurements (C). Three other groups were treated with placebo in the same manner. The tracheal responsiveness to ovalbumin and total and differential white blood cells of three placebo groups were significantly higher than those of control group $(P<0.001 \mathrm{for}$ all cases). Tracheal responsiveness to ovalbumin and total and differential white blood cell in treated groups with fluticasone propionate and salmeterol were significantly decreased compared to those of placebo groups (nonsignificant to $P<0.001$ ). The improvement in all variables in treatment groups $\mathrm{A}$ and $\mathrm{C}$ were more pronounced than group $\mathrm{B}$. The results showed that fluticasone propionate and salmeterol had a prevention effect on tracheal hyperresponsiveness to ovalbumin and lung inflammation which was more pronounced when administered during than after sensitization.
\end{abstract}

\section{Introduction}

The most important characteristic feature of asthma is a chronic inflammatory disorder of the airway [1] which leads to airway hyperresponsiveness (AHR) [2]. Asthma is a twocomponent disease including airway inflammation [3] and smooth muscle dysfunction [4]. Therefore, the most effective treatment is a drug which targets both components of the disease.

The combination of long acting $\beta$-agonists (LABA) and inhaled corticosteroid is more effective in treatment of asthma than increasing the dose of inhaled corticosteroid
(ICS) [5-8]. Suppression of the inflammatory process by LABA is also indicated in in vitro and in vivo animal studies [9-11]. Treatment with fluticasone propionate (FP) and salmeterol (SM) improved allergen-induced airway remodeling [12] and was able to control peripheral blood Tcell activation in asthmatic patients more efficiently [12]. Bidirectional interaction between $\beta$-agonists and steroids on various pathophysiologic aspects of asthma was documented previously $[13,14]$.

It was well documented that regular treatment with FP and SM combination resulted in continuous improvement in AHR with maintenance of asthma control in the majority of 
patients [15-17]. However, there are still many questions to be answered in this field. Most studies examined the effect of FP and SM combination on lung inflammation and airway responsiveness administered after clinical manifestation of asthma both in human [15-17] and in animal models [18] and only in few studies the effect of combined therapy was examined during sensitization in animal [19].

However, the effect of combined therapy, administered during, or after sensitization on the asthmatic airway inflammation is not compared yet. Therefore, in this study, the effect of an inhaled corticosteroid, fluticasone propionate and long acting $\beta$-agonist, salmetrol during and after sensitization of guinea pigs was investigated in tracheal responsiveness to ovalbumin (OA) and total and differential white blood cell (WBC) in bronchoalveolar lavage. In addition, the effect of an allergen-free period on the efficacy of combined therapy was also examined.

\section{Materials and Methods}

2.1. Animal Sensitization and Animal Groups. Guinea pigs were sensitized to (OA) as previously described [20-22]. Briefly, $10 \mathrm{mg}$ OA (Sigma Chemical Ltd, UK) and $100 \mathrm{mg}$ $\mathrm{Al}(\mathrm{OH})_{3}$ dissolved in $1 \mathrm{~mL}$ saline were administered via i.p injection on day one and seven. The animals were exposed to an aerosolized OA solution $4 \%$ for $18 \pm 1$ days, each day $4 \mathrm{~min}$ from day 17.

The aerosol was administered in a closed chamber, dimensions $30 \times 20 \times 20 \mathrm{~cm}$. The study was approved by the ethical committee of the Mashhad University of Medical Sciences.

2.2. Animal Groups. Guinea pigs were randomly divided into seven groups ( $n=7$ for each group) as follows (Figure 1).

(i) Control group (group $\mathrm{C}$ ): receiving $\mathrm{Al}(\mathrm{OH})_{3}$ alone dissolved in $1 \mathrm{~mL}$ normal saline and inhaled saline aerosol instead of OA.

(ii) Treatment and placebo groups A: treated with $250 \mu \mathrm{g}$ inhaled FP twice/day $+100 \mu \mathrm{g}$ inhaled SM twice/day or placebo (composition; CFC-free propellant HFA as4a; 1,1,1,2-Tetra fluoro ethane) (GlaxoSmithKline Research Triangle, NC) during sensitization period for 18 days.

(iii) Treatment and placebo groups B: treated with FP + $\mathrm{SM}$ or placebo after sensitization period for 18 days.

(iv) Treatment and placebo groups C: treated with FP + SM or placebo during sensitization period and evaluated with 18 days delay.

Aerosol FP and placebo were administered using ordinary canister through a modified spacer as previously described [23].

\section{Experimental Design}

3.1. Tissue Preparations. Guinea pigs were sacrificed and their trachea was removed. Each trachea was cut into 10 rings (each containing 2-3 cartilaginous rings). All the rings were then cut open opposite the tracheal muscle and sutured together to form a tracheal chain [24].

The tissue was then suspended in a $10 \mathrm{~mL}$ organ bath (Schuler organ bath type 809, March-Hugstetten, Germany) containing Krebs-Henseliet solution of the following composition (mM): $\mathrm{NaCl} 120, \mathrm{NaHCO}_{3} 25, \mathrm{MgSO}_{4} 0.5, \mathrm{KH}_{2} \mathrm{PO}_{4} 1.2$, $\mathrm{KCl} 4.72, \mathrm{CaCl}_{2} 2.5$, and dextrose 11. The Krebs solution was maintained at $37^{\circ} \mathrm{C}$ and gassed with $95 \% \mathrm{O}_{2}$ and $5 \% \mathrm{CO}_{2}$. The tissue was suspended under an isotonic tension of $1 \mathrm{~g}$ and allowed to equilibrate for at least $1 \mathrm{~h}$, while it was washed with Krebs solution every 15 mins.

Responses were measured using the Vernier control-type $850 \mathrm{~N}$ sensor with sensitivity range of $0-20 \mathrm{~g}$ and resolution of $0.2 \mathrm{~mm} /$ turn (Hugo-Sachs Elektronik, Germany) and amplified by amplifier (ML/118 quadribridge amp, MarchHugstetten, Germany) and recorded by powerlab (ML-750, 4 channel recorder, March- Hugstetten, Germany).

3.2. Measurement of Tracheal Response to Ovalbumin. The tracheal response to $0.1 \%$ solution of OA was measured as follows: $0.25 \mathrm{~mL}$ of $4 \%$ OA solution was added to the $10 \mathrm{~mL}$ organ bath. The degree of tracheal chain contraction was recorded after $2.5 \mathrm{mins}$ and was expressed as proportion (percentage) to contraction obtained by $10 \mu \mathrm{M}$ methacholine.

3.3. Lung Lavage and Its White Blood Cells Count. The lungs were lavaged with $2 \mathrm{~mL}$ of saline for 5 times (total: $10 \mathrm{~mL}$ ). One $\mathrm{mL}$ of bronchoalveolar lavage (BAL) fluid was stained with Turk solution ( $1 \mathrm{~mL}$ of Glacial Acetic Acid, $1 \mathrm{~mL}$ of Gentian Violet Solution 1\% and $100 \mathrm{~mL}$ Distilled Water) and total WBC was counted in duplicate in a hemocytometer (in a Burker chamber).

The remaining BAL was centrifuged at $2500 \times \mathrm{g}$ at $4^{\circ} \mathrm{C}$ for $10 \mathrm{~min}$. The supernatant was removed. The smear was prepared from the cells and stained with Wright-Giemsa. Differential cell analysis was carried out under a light microscope by counting 400 cells and the percentage was calculated.

3.4. Statistical Analysis. The percent improvement in each treatment group was calculated; in cases, the treatment group's data was greater than that of corresponding placebo as calculated by $\left(\left[\left(\right.\right.\right.$ Treatment $_{\mathrm{A} 1}-$ Placebo $\left._{\mathrm{A} 1}\right) /$ Placebo $\left.\left._{\mathrm{A} 1}\right] \times 100\right)$; in cases, the treatment group's data were lower than that of corresponding placebo, and the improvement was calculated by $\left(\left[\left(\right.\right.\right.$ Placebo $_{\mathrm{A} 1}-$ Treatment $\left._{\mathrm{A} 1}\right) /$ Treatment $\left.\left._{\mathrm{A} 1}\right] \times 100\right)$.

All data were quoted as mean \pm SEM. Percent improvements were achieved as follows: in cases, the treatment data was greater than that of corresponding placebo, the data obtained in treatment group minus the data obtained in corresponding placebo group was divided by the data obtained in the same placebo group and multiplied by 100 (e.g., $\left[\left(\right.\right.$ Treatment $_{\mathrm{A} 1}-$ Placebo $\left._{\mathrm{A} 1}\right) /$ Placebo $\left.\left._{\mathrm{A} 1}\right] \times 100\right)$. In cases, the treatment data was lower than that of corresponding placebo; the data obtained in placebo group minus the data obtained in corresponding treatment group was divided by the data obtained in the same treatment group and multiplied by 100 (e.g., $\left[\left(\right.\right.$ Placebo $_{\mathrm{A} 1}-$ Treatment $\left._{\mathrm{A} 1}\right) /$ Treatment $\left.\left._{\mathrm{A} 1}\right] \times 100\right)$. 


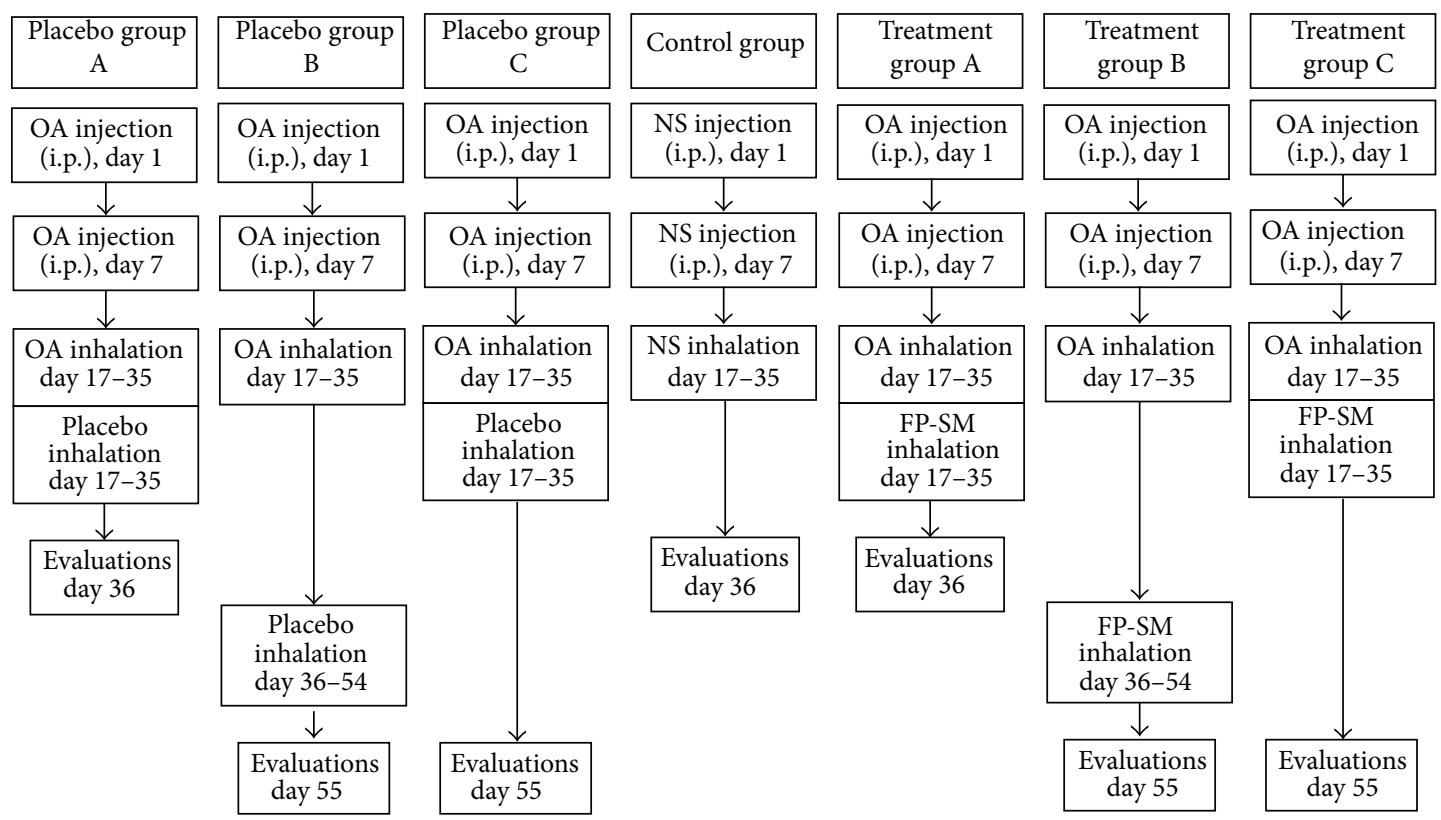

FIGURE 1: Description of control, three placebo, and three treated sensitized groups. FP: fluticasone propionate (250 $\mu$ g); SM: salmeterol $(100 \mu \mathrm{g}) ;$ OA: ovalbumin; NS: normal saline.

TABle 1: Percent improvements in tracheal responses to OA and total and differential count of white blood cells in lung lavage changes in three treatment groups $\mathrm{A}, \mathrm{B}$, and C.

\begin{tabular}{lccc}
\hline Parameters & Treatment group A & Treatment group B & Treatment group C \\
\hline OVA & $102.71 \pm 23.86$ & $11.14 \pm 3.09^{++}$ & $35.14 \pm 12.73^{*}$ \\
Total WBC & $109.42 \pm 29.15$ & $194 \pm 20.03$ & $233.28 \pm 33.99^{*}$ \\
Eosinophil \% & $204.85 \pm 17.04$ & $44.71 \pm 17.85^{+++}$ & $101.42 \pm 26.13^{\text {gg }}$ \\
Neutrophil \% & $22.42 \pm 4.20$ & $12.14 \pm 4.96$ & $15.71 \pm 3.93$ \\
Monocyte \% & $495.42 \pm 127.90$ & $120.42 \pm 31.25^{++}$ & $155.71 \pm 25.96^{*}$ \\
Lymphocyte \% & $59.28 \pm 9.31$ & $20.71 \pm 3.22^{++}$ & $20.71 \pm 9.33^{* *}$ \\
\hline
\end{tabular}

Values are quoted as mean \pm SEM. Percent improvements were achieved as follows. In cases, the treatment data was greater than that of corresponding placebo; the data obtained in treatment group minus the data obtained in corresponding placebo group was divided by the data obtained in the same placebo group and multiplied by 100 (e.g. [(Treatment ${ }_{\mathrm{A} 1}-$ Placebo $\left.\left.\left._{\mathrm{A} 1}\right) / \mathrm{Placebo}_{\mathrm{A} 1}\right] 100\right)$. In cases, the treatment data was lower than that of corresponding placebo; the data obtained in placebo group minus the data obtained in corresponding treatment group was divided by the data obtained in the same treatment group and multiplied by 100 (e.g. [(Placebo ${ }_{\mathrm{A} 1}-$ Treatment $\left._{\mathrm{A1}}\right) /$ Treatment $\left.\left._{\mathrm{A} 1}\right] 100\right)$. Comparisons of the data between three treatment groups were done using one-way analysis of variance (ANOVA) with Tukey-Kramer posttest.

Statistical significance for the difference between the data of group A versus group B: ${ }^{++} P<0.01,{ }^{+++} P<0.001$.

Statistical significance for the difference between the data of group A versus group $C:{ }^{*} P<0.5,{ }^{* *} P<0.01$.

Statistical significance for the difference between the data of group B versus group C: ${ }^{99} P<0.01$.

The data of three placebo groups were compared with the data of treated guinea pigs using unpaired $t$-test. The comparison of data between three treatment groups, three placebo groups and six groups of animals treated with the FP and SM and placebo with control animals, was done using one-way analysis of variance (ANOVA) with Tukey-Kramer posttest. Significance was accepted at $P<0.05$. All statistical analyses was performed using Instat software version 3.00 (GraphPad Software, San Diego, California, USA).

\section{Results}

4.1. Tracheal Response to Ovalbumin. Tracheal responses to $\mathrm{OA}$ in all placebo groups (A, B, and $\mathrm{C}$ ) were significantly higher than control group $(P<0.001$ for all cases), (Figure 2). Tracheal responses to $\mathrm{OA}$ in treatment groups $\mathrm{A}$ and $\mathrm{C}$ were significantly lower than corresponding placebo groups $(P<0.001$ and $P<0.01$ resp.). Improvement of tracheal responsiveness to $\mathrm{OA}$ in treatment groups $\mathrm{B}$ and $\mathrm{C}$ was significantly lower than that of group $\mathrm{A}(P<0.01$ and $P<$ 0.05 , resp.), (Table 1 ).

4.2. Total and Differential White Blood Cell Count. The mean values of total white blood cell (WBC) as well as the percentage of neutrophils and eosinophils were significantly higher but percentage of lymphocytes and monocytes in BAL of placebo groups $\mathrm{A}, \mathrm{B}$ and $\mathrm{C}$ were significantly lower than those of control group $(P<0.01$ to $P<0.001)$, (Figures 3 and 


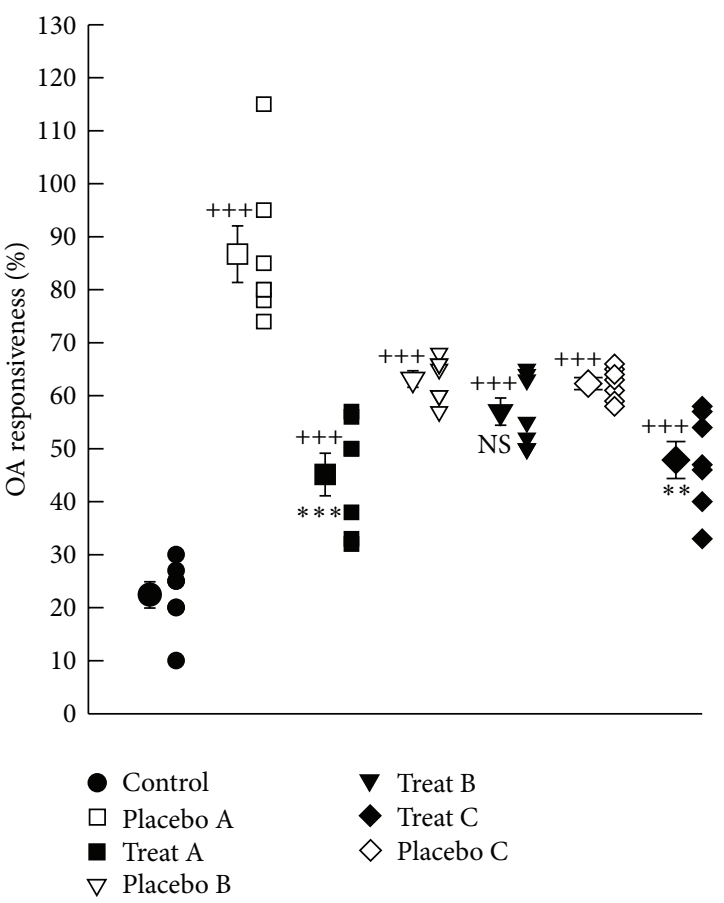

Figure 2: Individual values and mean \pm SEM (big symbols with bars) of tracheal response to ovalbumin (OA) in control group and sensitized groups treated with fluticasone + salmeterol and placebo during (A), after (B), and during sensitization period and 18 days delay (C). Tracheal responsiveness to OA was measured by percent contraction obtained by $0.1 \%$ solution of OA compared to $10 \mu \mathrm{M}$ methacholine. Comparisons of the data between control and three treated and three placebo groups were done using one-way analysis of variance (ANOVA) with Tukey-Kramer posttest, ${ }^{++}: P<0.01$, and ${ }^{+++}: P<0.001$. Comparison of the data between each treated group with fluticasone propionate + salmeterol and corresponding placebo group was done using unpaired $t$-test, ${ }^{* *}: P<0.01,{ }^{* * *}: P<0.001$, NS: nonsignificant.

4(a)-4(d)). The total number of WBCs in treatment groups A, $\mathrm{B}$, and $\mathrm{C}$ showed significant improvement compared to that of corresponding placebo groups $(P<0.001$ for all cases), (Figure 3). Improvement of change in total white blood cell (WBC) in BAL in treatment group A was significantly lower than that of treatment group C $(233.28 \pm 33.99, P<0.05)$, (Table 1).

There were a significant increase in the percentage of monocytes in all treatment groups and a significant decrease in the percentage of eosinophils and further decrease of lymphocytes in treatment group A compared to the corresponding placebo groups $(P<0.05$ to $P<0.001)$, (Figure 4(d)).

The mean values of improvement in percentage of eosinophils, lymphocytes, and monocytes in BAL of treatment group A were significantly greater than those of treatment protocol B $(P<0.01$ to $P<0.001)$. Improvement in the percentage of lymphocytes and monocytes in group A was also significantly greater than that of treatment group C $(P<0.01$ and $P<0.05$ resp.), (Table 1$)$. In addition, the improvement in the percentage of eosinophils in BAL

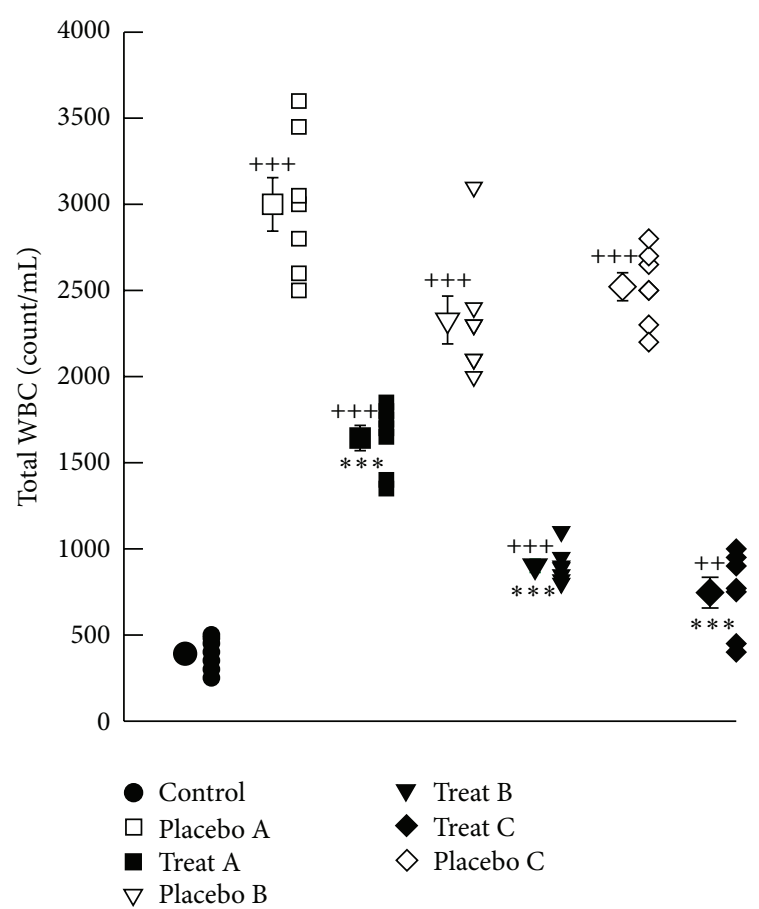

FIGURE 3: Individual values and mean \pm SEM (big symbols with bars) of total WBC count (count/mL) (b) in control group and sensitized groups treated with fluticasone + salmeterol and placebo during (A), after (B) and during sensitization period and 18 days delay (C). Tracheal responsiveness to OA was measured by percent contraction obtained by $0.1 \%$ solution of OA compared to $10 \mu \mathrm{M}$ methacholine. Comparison of the data between control and three treated and three placebo groups were done using one way analysis of variance (ANOVA) with Tukey-Kramer posttest, ${ }^{++}: P<0.01$, and ${ }^{+++}: P<0.001$. Comparison of the data between each treated group with fluticasone propionate + salmeterol and corresponding placebo group was done using unpaired $t$ test, ${ }^{* *}: P<0.01,{ }^{* * *}: P<0.001$, NS: nonsignificant.

of treatment group $\mathrm{C}$ was significantly greater than that of treatment group B $(P<0.01)$, (Table 1$)$.

\section{Discussion}

Tracheal response to $\mathrm{OA}$, total $\mathrm{WBC}$ count in lung lavage and percentage of eosinophils and neutrophils increased but percentages of, lymphocytes and monocytes decreased in sensitized compared to control animals which were similar to the results of the previous studies $[22,25,26]$. The reduction in lymphocyte seen in this study may arise from the increase in total WBC number $[27,28]$.

The most effective agent in asthma therapy is a drug which targets both airway inflammation and smooth muscle dysfunction of the disease. Therefore, the effect of FP and SM on the tracheal responsiveness to OA, total differential WBC count which was administered during and after sensitization and during sensitization with 18 days delay in measurements was examined in this study.

The small effect of FP and SM on percentages of neutrophils in BAL fluid of sensitized animals observed in the 

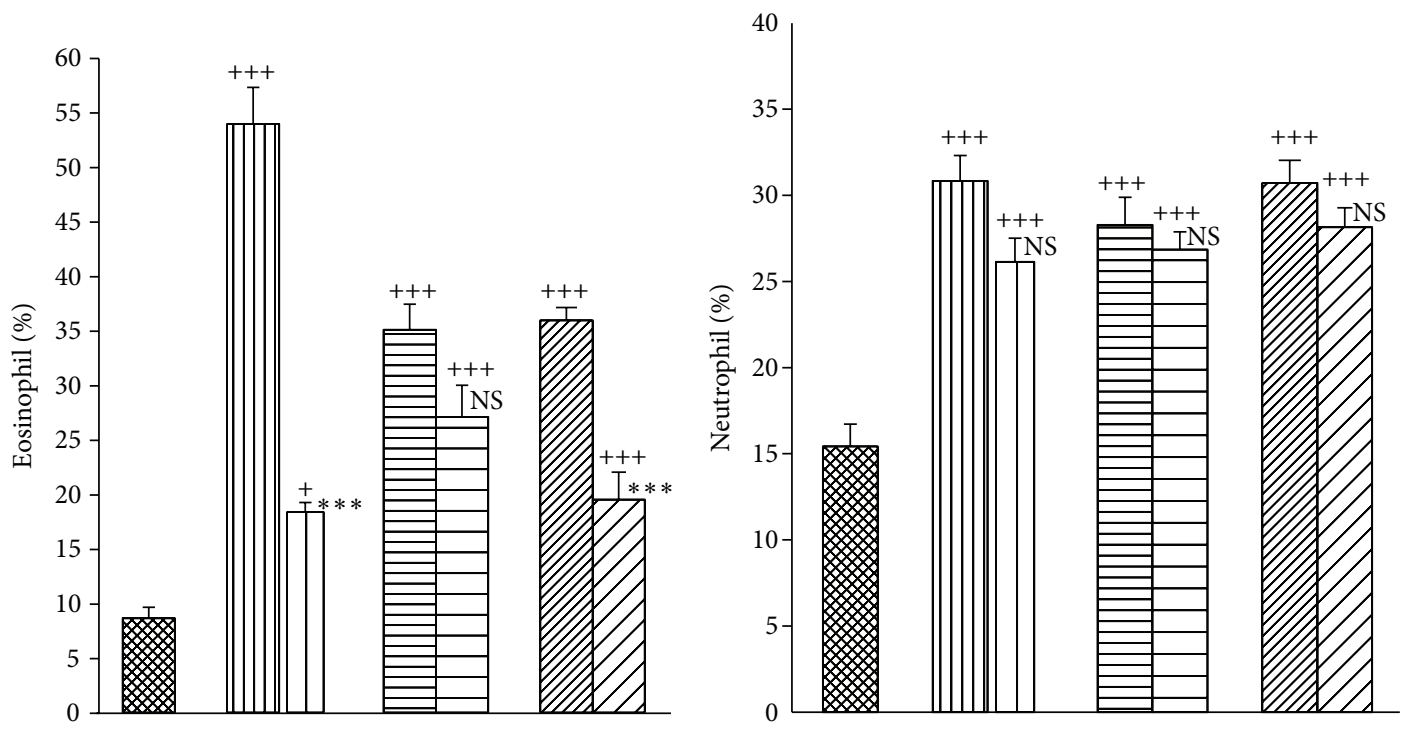

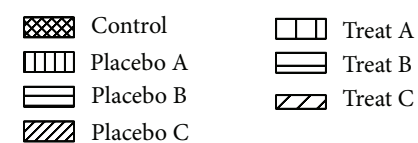

(a)

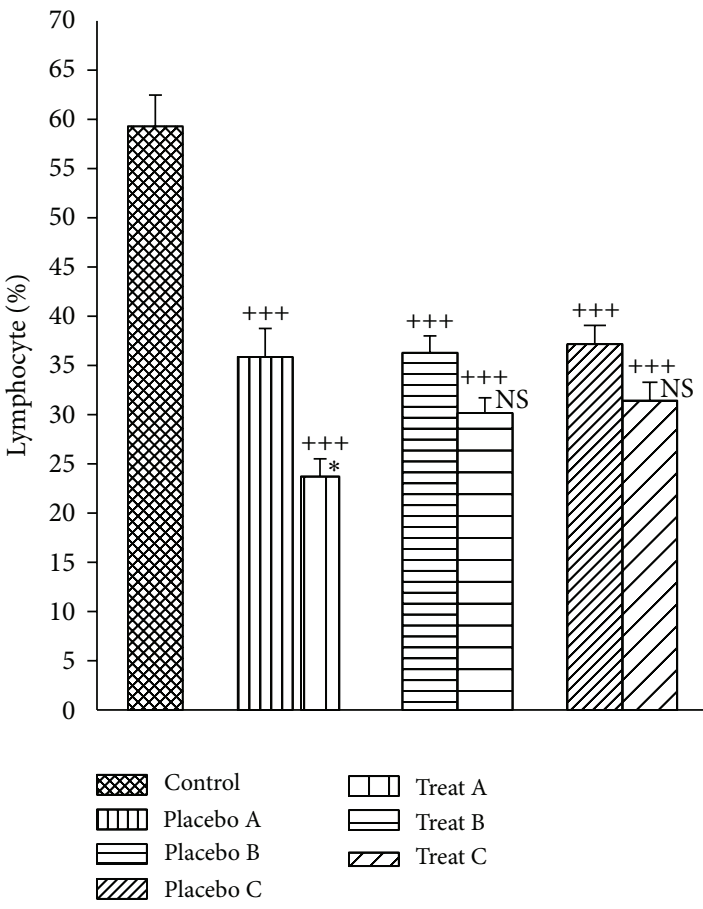

(c)

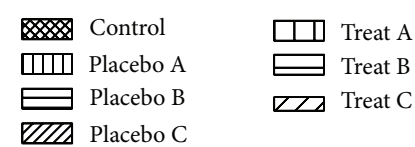

(b)

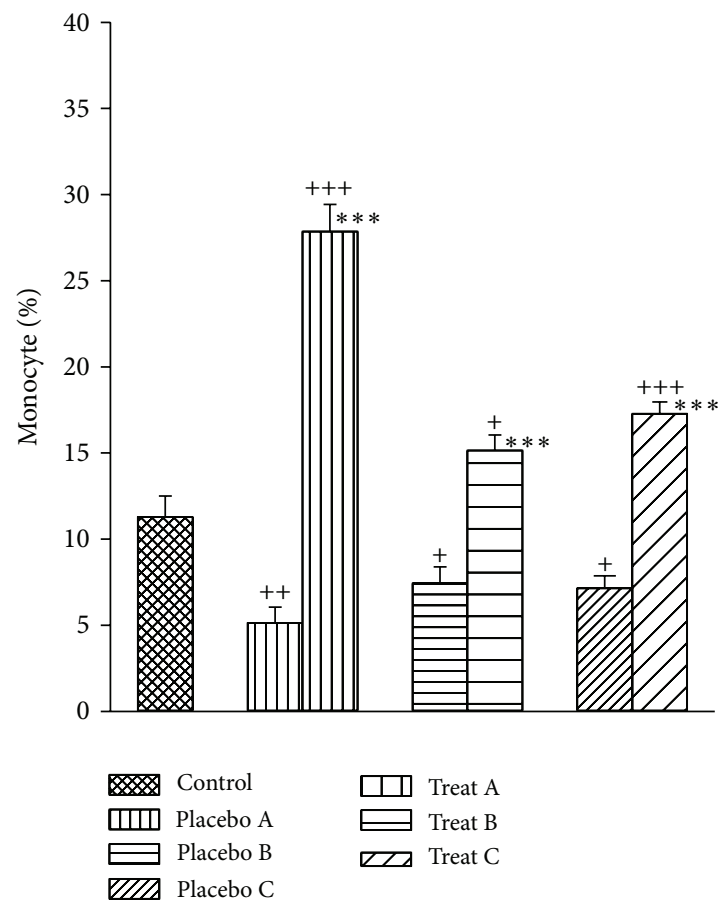

(d)

Figure 4: Mean \pm SEM of the percentages of eosinophils (a), neutrophils (b), lymphocytes (c), and monocytes (d) of lung lavage in control group and sensitized groups treated with fluticasone + salmeterol and placebo during (A), after (B), and during sensitization period and 18 days delay $(\mathrm{C})$. Comparison of the data between control and three treated with fluticasone propionate + salmeterol and three placebo groups was done using one-way analysis of variance (ANOVA) with Tukey-Kramer posttest. ${ }^{+}: P<0.05,{ }^{++}: P<0.01$, and ${ }^{+++}: P<0.001$. Comparison of the data between each treated group with fluticasone propionate + salmeterol and corresponding placebo group was done using unpaired $t$-test, NS: nonsignificant, ${ }^{*}: P<0.05,{ }^{* * *}: P<0.001$, and NS: nonsignificant. 
present study may suggest that fluticasone propionate prolongs human neutrophil survival by inhibiting apoptosis by having an effect on glucocorticoid receptor [29]. Reduction in the percentages of lymphocytes in BAL of all treatment groups could be due to apoptotic effect of FP and SM which was seen in cultured lymphocytes too [30]. The increase in the percentage of monocytes in all treatment groups seen in the present study was different from the previous observed effect of corticosteroids, that is, reducing recruitment of monocytes to the airways [31]. But it could be due to reduction of total WBC count.

The effect of FP and SM on the tracheal responsiveness to $\mathrm{OA}$ and total and differential WBC count in lung lavage of sensitized guinea pigs seen in the present study, was supported by those who indicated that adding LABA leads to greater improvement in different parameters of asthma than increasing the dose of inhaled corticosteroid (ICS) $[5,8,9,11-$ $14,30]$. However, the effect of FP and SM administered during (with measuring parameters immediately and after 18 days delay) and after sensitization of guinea pigs was evaluated which was the novelty of the present study.

In placebo group A (sensitized animals treated with inhaled placebo during sensitization, PA), most parameters were greater than those of placebo group B (sensitized animals treated with inhaled placebo after sensitization, PB) and placebo group C (sensitized animals treated with inhaled placebo during sensitization but measurement of different parameters were performed 18 days after the end of sensitization period, PC). There was greater sensitization in $\mathrm{PA}$ compared to PB and PC. The cause of these findings is perhaps due to an allergen-free period which is supported by the effect of allergen prevention in control of asthma disease [32] and allergen-free period in an animal study [33].

The novelty of the present study is the evaluation of the effect of FP and SM administration after (examining parameters immediately or with 18 days delay) and during sensitization of guinea pigs. The effect of an allergen free period in animals treated during sensitization on the results of combined therapy was also examined. The improvement in most parameters in treatment group A and C (TA and TC) was greater than group $\mathrm{B}$ (TB). The cause of these findings is perhaps due to administration of FP and SM during sensitization which indicates the importance of the early as possible asthma therapy. In fact a permanent loss of pulmonary function or even induced remission in some patients in early treatment of airway inflammation is observed previously [28] which supports these findings. The cause of less improvement in total WBC in TA group compared to TB is perhaps due to the greater change in this group. There was less improvement in some parameters in group TC compared to TA. The cause of these results is perhaps a nontreated period of 18 days in this group which emphasizes the role of ongoing treatment in asthmatic patients. The results also showed incomplete prevention of tracheal responsiveness to OA and total and differential WBC in treated sensitized guinea pigs with FP and SM either during or after sensitization which are other important findings of the present study.

In a previous study, the effect of FP alone administered during or after sensitization was examined [34]. The present study aimed to investigate the following: (1) is the combination of fluticasone propionate and salmeterol different from fluticasone propionate alone? and (2) does an allergen-free period in animals treated during sensitization affect the results? Comparison of the results of two studies showed that treatment of sensitized guinea pigs with combination of FP and SM during sensitization leads to more improvement in most variables except neutrophil, count compared to animals treated with only FP. In sensitized animals treated with combination of the two drugs after sensitization, also improvement in total WBC was greater than those treated with FP. In addition, there was no significant difference in eosinophil and monocyte counts between two drugs treated after sensitization. However, improvement in tracheal responsiveness to OA, neutrophil and lymphocyte counts was greater in treated animals with FP alone than combination of FP and SM after sensitization. Therefore, the results of both studies showed that treatment during sensitization is more effective than after sensitization. In addition, the results showed that treatment of sensitized animals with FP and SM is more effective than FP alone especially in the group treated during sensitization.

While asthma is an airway inflammation disorder [1], in further studies, the effect of FP and SM administered during or after sensitization on serum and lung lavage levels of inflammatory mediators should be examined. In the present study, tracheal responsiveness was measured, but, in asthma, disorder of mostly small and medium airways is present. This limitation should be addressed in further studies by in vivo measurement of airway resistance in sensitized animals treated with FP and SM during or after sensitization. In addition, all aspects of asthma are not produced in sensitized animals. Therefore, related clinical studies are needed to fully address the effect of administration time of drugs on the management of asthma.

\section{Conclusion}

The results showed that FP and SM had a preventive effect on the tracheal hyperresponsiveness to OA and lung inflammation. This preventive effect was greater when drugs were administered during sensitization. The results indicate that asthma therapy should be started as soon as possible early during the development of airway inflammation in asthmatic patients. The role of an allergen-free environment in the treatment of asthma is also suggested.

\section{Conflict of Interests}

The authors declare that there is no conflict of interests regarding the publication of this paper.

\section{Acknowledgments}

This study was financially supported by the Research Department of Mashhad University of Medical Sciences. 


\section{References}

[1] W. Busse, S. P. Banks-Schlegel, and G. L. Larsen, "Childhoodversus adult-onset asthma," American Journal of Respiratory and Critical Care Medicine, vol. 151, no. 5, pp. 1635-1639, 1995.

[2] P. Padrid, S. Snook, T. Finucane et al., "Persistent airway hyperresponsiveness and histologic alterations after chronic antigen challenge in cats," American Journal of Respiratory and Critical Care Medicine, vol. 151, no. 1, pp. 184-193, 1995.

[3] C. Kelly, C. Ward, C. S. Stenton, G. Bird, D. J. Hendrick, and E. H. Walters, "Number and activity of inflammatory cells in bronchoalveolar lavage fluid in asthma and their relation to airway responsiveness," Thorax, vol. 43, no. 9, pp. 684-692, 1988.

[4] M. E. Levine, "Combination of inhaled steroid and long-acting beta-2-agonist therapy-use and limitations," Current Allergy and Clinical Immunology, vol. 25, no. 2, pp. 72-75, 2012.

[5] S. Shrewsbury, S. Pyke, and M. Britton, "Meta-analysis of increased dose of inhaled steroid or addition of salmeterol in symptomatic asthma (MIASMA)," British Medical Journal, vol. 320, no. 7246, pp. 1368-1373, 2000.

[6] J. Matz, A. Emmett, K. Rickard, and C. Kalberg, "Addition of salmeterol to low-dose fluticasone versus higher-dose fluticasone: an analysis of asthma exacerbations," The Journal of Allergy and Clinical Immunology, vol. 107, no. 5, pp. 783-789, 2001.

[7] J. C. Kips, B. J. O’Connor, M. D. Inman, K. Svensson, R. A. Pauwels, and P. M. O'Byrne, "A long-term study of the antiinflammatory effect of low-dose budesonide plus formoterol versus high-dose budesonide in asthma," American Journal of Respiratory and Critical Care Medicine, vol. 161, no. 3, pp. 996$1001,2000$.

[8] N. N. Jarjour, S. J. Wilson, S. M. Koenig et al., "Control of airway inflammation maintained at a lower steroid dose with 100/50 $\mu \mathrm{g}$ of fluticasone propionate/salmeterol," The Journal of Allergy and Clinical Immunology, vol. 118, no. 1, pp. 44-52, 2006.

[9] L.-P. Boulet, J. Chakir, J. Milot, M. Boutet, and M. Laviolette, "Effect of salmeterol on allergen-induced airway inflammation in mild allergic asthma," Clinical and Experimental Allergy, vol. 31, no. 3, pp. 430-437, 2001.

[10] H. Sarir, E. Mortaz, K. Karimi, M. Johnson, F. P. Nijkamp, and G. Folkerts, "Combination of fluticasone propionate and salmeterol potentiates the suppression of cigarette smokeinduced IL-8 production by macrophages," European Journal of Pharmacology, vol. 571, no. 1, pp. 55-61, 2007.

[11] R. Singam, P. K. Jena, S. Behera et al., "Combined fluticasone propionate and salmeterol reduces RSV infection more effectively than either of them alone in allergen-sensitized mice," Virology Journal, vol. 3, no. 1, p. 32, 2006.

[12] N. J. Vanacker, E. Palmans, R. A. Pauwels, and J. C. Kips, "Effect of combining salmeterol and fluticasone on the progression of airway remodeling," American Journal of Respiratory and Critical Care Medicine, vol. 166, no. 8, pp. 1128-1134, 2002.

[13] G. P. Anderson, "Interactions between corticosteroids and $\beta$ adrenergic agonists in asthma disease induction, progression, and exacerbation," American Journal of Respiratory and Critical Care Medicine, vol. 161, no. 3, part 2, pp. S188-S198, 2000.

[14] D. Giannini, E. Bacci, F. L. Dente et al., "Inhaled beclomethasone dipropionate reverts tolerance to the protective effect of salmeterol on allergen challenge," Chest, vol. 115, no. 3, pp. 629$634,1999$.
[15] P. Chanez, R. Stallaert, E. Reznikova, P. Bloemen, L. Adamek, and G. Joos, "Effect of salmeterol/fluticasone propionate combination on airway hyper-responsiveness in patients with wellcontrolled asthma," Respiratory Medicine, vol. 104, no. 8, pp. 1101-1109, 2010.

[16] P. J. Barnes, "Scientific rationale for using a single inhaler for asthma control," European Respiratory Journal, vol. 29, no. 3, pp. 587-595, 2007

[17] A. J. Knox and K. Mortimer, "Combining inhaled glucocorticoids and long acting $\beta_{2}$-adrenoceptor agonists in asthma and COPD," British Journal of Pharmacology, vol. 153, no. 6, pp. 1085-1086, 2008.

[18] L. K. A. Lundblad, L. M. Rinaldi, M. E. Poynter et al., "Detrimental effects of albuterol on airway responsiveness requires airway inflammation and is independent of $\beta$-receptor affinity in murine models of asthma," Respiratory Research, vol. 12, no. 1, article 27, 2011.

[19] E. P. Riesenfeld, M. J. Sullivan, J. A. Thompson-Figueroa et al., "Inhaled salmeterol and/or fluticasone alters structure/function in a murine model of allergic airways disease," Respiratory Research, vol. 11, no. 1, article 22, 2010.

[20] A. Neamati, M. H. Boskabady, S. Mohaghegh Hazrati, M. R. Khakzad, and S. H. Moosavi, "The effect of natural adjuvants (G2, G2F) on lung inflammation of sensitized guinea pigs," Avicenna Journal of Phytomedicine, vol. 3, no. 4, pp. 364-370, 2013.

[21] M. H. Boskabady, S. Kiani, and M. R. Aslani, “Tracheal responsiveness to both isoprenaline and beta $_{2}$-adrenoreceptor blockade by propranolol in cigarette smoke exposed and sensitized guinea pigs," Respirology, vol. 11, no. 5, pp. 572-578, 2006.

[22] M. H. Boskabady and S. Kiani, "The effect of exposure of guinea pig to cigarette smoke and their sensitization in tracheal responsiveness to histamine and histamine receptor $\left(\mathrm{H}_{1}\right)$ blockade by chlorpheniramine," Pathophysiology, vol. 14, no. 2, pp. 97-104, 2007.

[23] R. L. Sorkness, J. L. Remus, and L. A. Rosenthal, "Systemic and pulmonary effects of fluticasone administered through a metered-dose inhaler in rats," The Journal of Allergy and Clinical Immunology, vol. 114, no. 5, pp. 1027-1032, 2004.

[24] M. H. Boskabady and M. R. Aslani, "Relaxant effect of Crocus sativus (saffron) on guinea-pig tracheal chains and its possible mechanisms," Journal of Pharmacy and Pharmacology, vol. 58, no. 10, pp. 1385-1390, 2006.

[25] D. I. Blyth, M. S. Pedrick, T. J. Savage, E. M. Hessel, and D. Fattah, "Lung inflammation and epithelial changes in a murine model of atopic asthma," American Journal of Respiratory Cell and Molecular Biology, vol. 14, no. 5, pp. 425-438, 1996.

[26] Y. Fujitani and A. Trifilieff, "In vivo and in vitro effects of SAR 943, a rapamycin analogue, on airway inflammation and remodeling," American Journal of Respiratory and Critical Care Medicine, vol. 167, no. 2, pp. 193-198, 2003.

[27] Z. Zhu, R. J. Homer, Z. Wang et al., "Pulmonary expression of interleukin-13 causes inflammation, mucus hypersecretion, subepithelial fibrosis, physiologic abnormalities, and eotaxin production," The Journal of Clinical Investigation, vol. 103, no. 6, pp. 779-788, 1999.

[28] S. H. Gavett, X. Chen, F. Finkelman, and M. Wills-Karp, "Depletion of murine $\mathrm{CD} 4{ }^{+} \mathrm{T}$ lymphocytes prevents antigeninduced airway hyperreactivity and pulmonary eosinophilia," American Journal of Respiratory Cell and Molecular Biology, vol. 10, no. 6, pp. 587-593, 1994. 
[29] X. Zhang, E. Moilanen, and H. Kankaanranta, "Beclomethasone, budesonide and fluticasone propionate inhibit human neutrophil apoptosis," European Journal of Pharmacology, vol. 431, no. 3, pp. 365-371, 2001.

[30] E. Pace, R. Gagliardo, M. Melis et al., "Synergistic effects of fluticasone propionate and salmeterol on in vitro T-cell activation and apoptosis in asthma," The Journal of Allergy and Clinical Immunology, vol. 114, no. 5, pp. 1216-1223, 2004.

[31] A. O. Magnan, L. G. Mély, C. A. Camilla et al., "Assessment of the Th1/Th2 paradigm in whole blood in atopy and asthma: increased IFN- $\gamma$-producing $\mathrm{CD}^{+} \mathrm{T}$ cells in asthma," American Journal of Respiratory and Critical Care Medicine, vol. 161, no. 6, pp. 1790-1796, 2000.

[32] A. Woodcock and A. Custovic, "Allergen avoidance: does it work?” British Medical Bulletin, vol. 56, no. 4, pp. 1071-1086, 2000.

[33] N. J. Vanacker, E. Palmans, J. C. Kips, and R. A. Pauwels, "Fluticasone inhibits but does not reverse allergen-induced structural airway changes," American Journal of Respiratory and Critical Care Medicine, vol. 163, no. 3, part 1, pp. 674-679, 2001.

[34] M. H. Boskabady, M. J. Eslamizade, A. Tabatabaei, H. Nemati, and F. Mansouri, "Effect of inhaled fluticasone on lung inflammation administered during and after guinea pig sensitization," Archives of Bronconeumology, vol. 46, no. 5, pp. 215-222, 2010. 


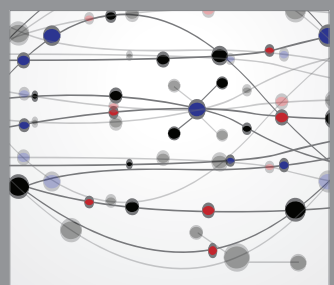

The Scientific World Journal
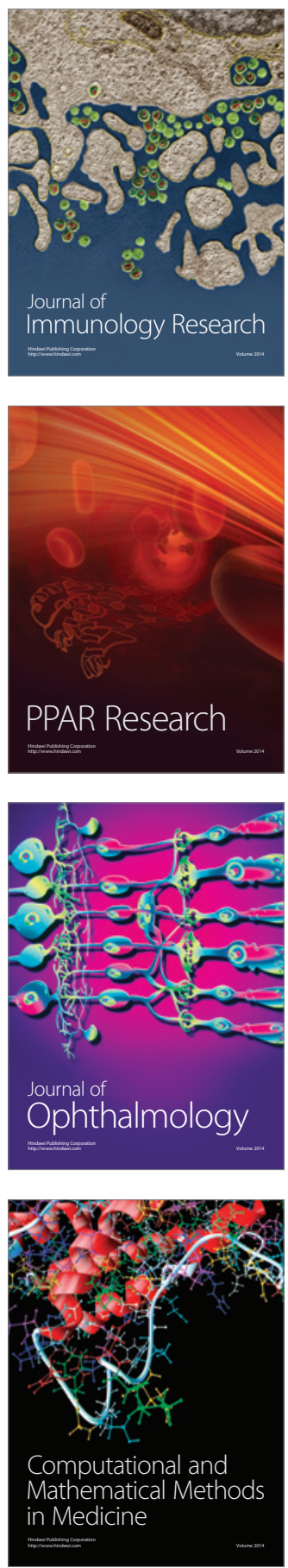

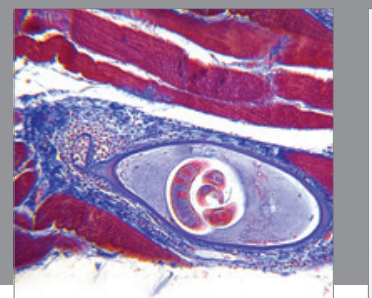

Gastroenterology

Research and Practice
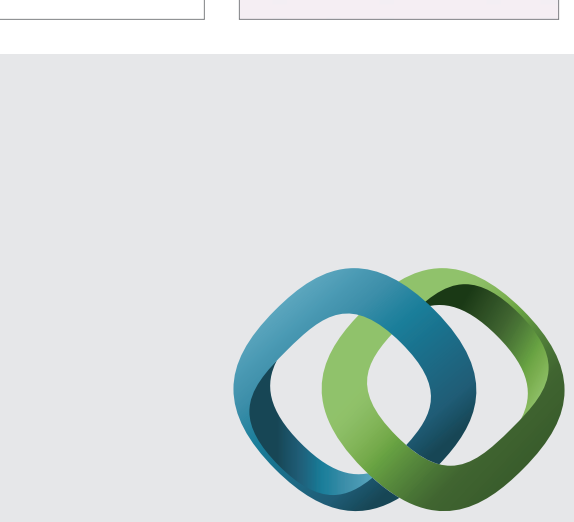

\section{Hindawi}

Submit your manuscripts at

http://www.hindawi.com
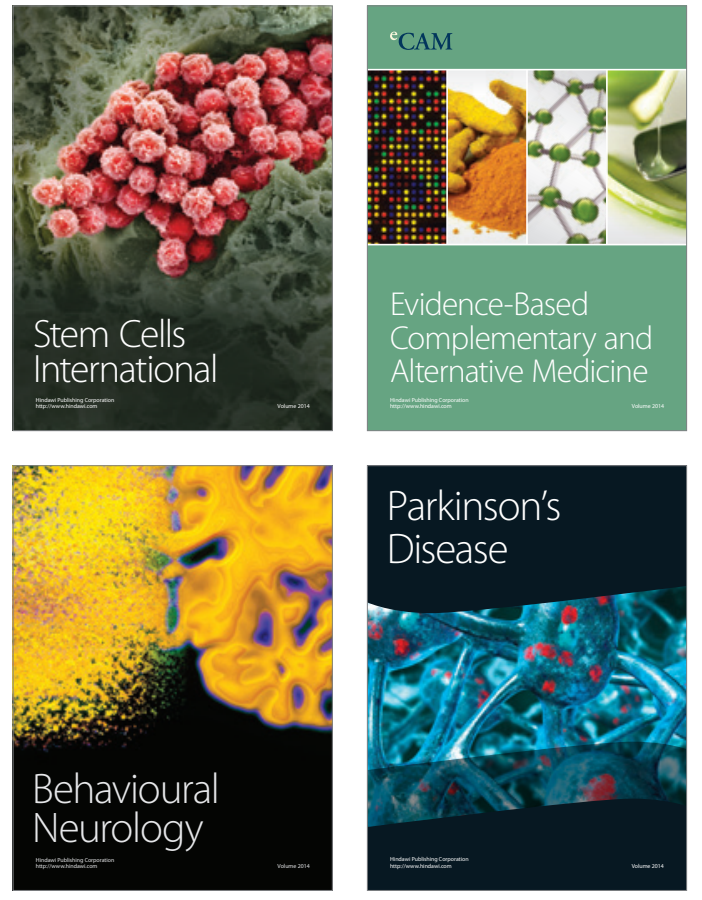
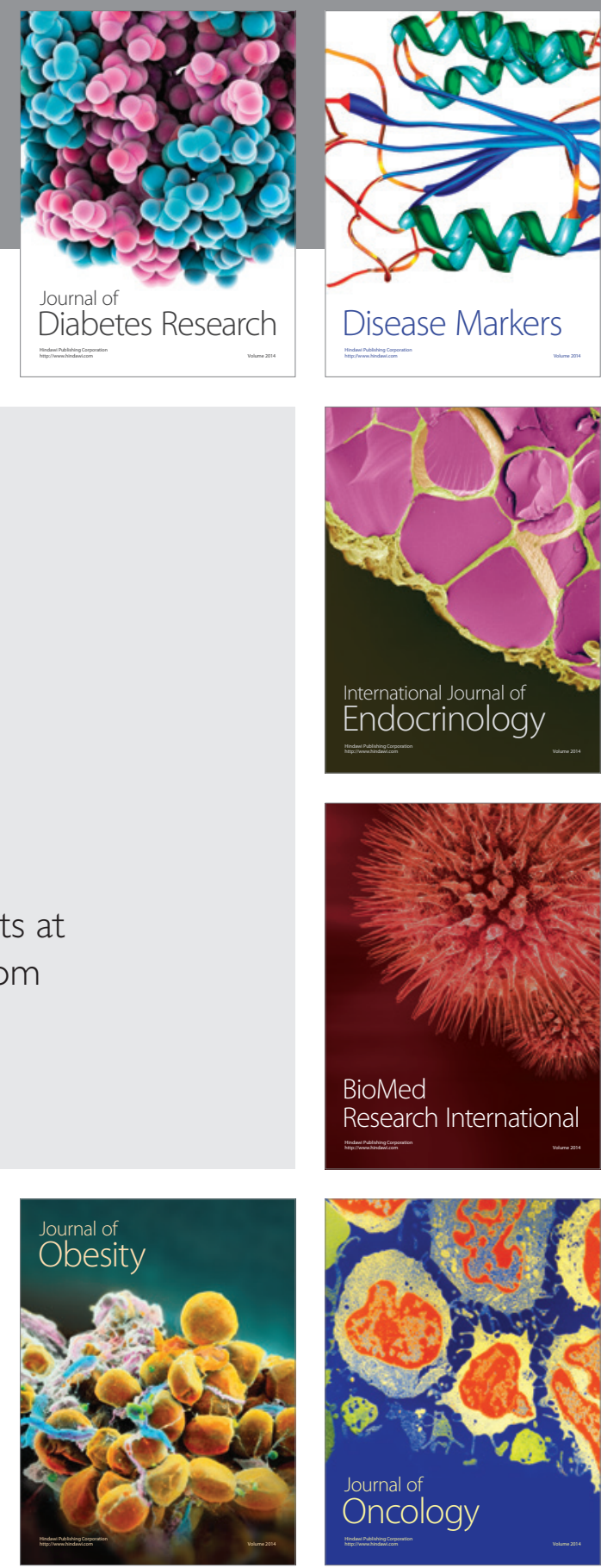

Disease Markers
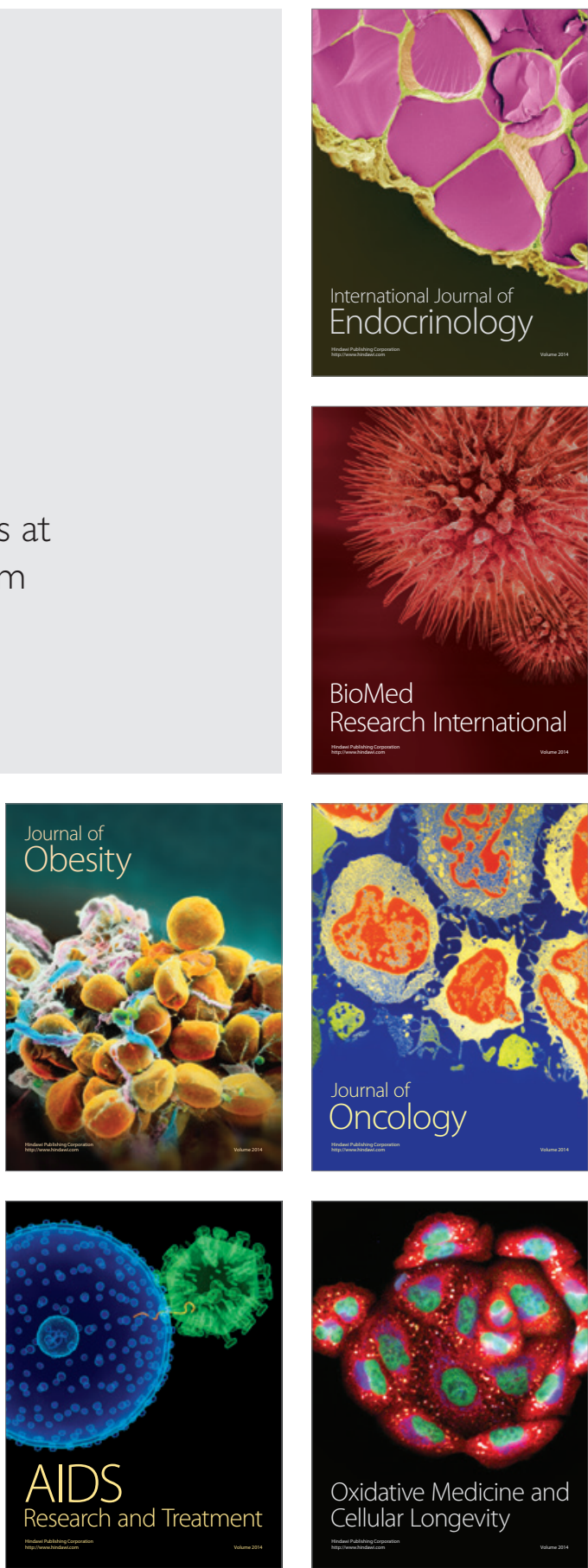